\title{
SOBRE ESTRATEGIAS DE ENSEÑANZA DE LAS CORRESPODENCIAS MORFOSINTÁCTICAS ENTRE EL ÁRABE Y EL ESPAÑOL A ESTUDIANTES ÁRABO-PARLANTES
}

Ziyad Muhammad Gogazeh

Universidad de Jordania

\begin{abstract}
This article based on a personal academic experience in teaching the course: translation from Arabic to Spanish and vice versa at the Department of Spanish in the University of Jordan. The work sheds light on the most important problems that arabic-speacking students face at the time of carrying out a translation between the two languages. A detailed contrastive analysis has also been realized between the two languages at various linguistic levels emphasizing the most important peculiarities of each one.
\end{abstract}

Según la teoría de la traducción, cada material textual objeto de traducción se divide en dos partes fundamentales: la primera parte es el estilo y la segunda es el contenido o las ideas o el mensaje del texto ${ }^{1}$. Y no cabría la mínima duda sobre la unanimidad de los teóricos de la ciencia de la traductología de que el contenido semántico es el componente mas importante al que se tiene que dedicar todo cuidado y fidelidad.

Como se sabe, cada material textual tiene por objetivo trasladar un cierto mensaje y exponer algunas ideas. La tarea del traductor en este sentido es trasladar fielmente a la lengua receptora este mensaje sin desvío ninguno de las ideas del texto original en la lengua fuente.

En este artículo, fruto de una experiencia personal en la enseñanza de la asignatura Traducción del árabe al español y viceversa en la Universidad de Jordania, queremos arrojar luz sobre los problemas más importantes que padecen los estudiantes áraboparlantes a la hora de traducir entre los dos idiomas objeto de estudio.

Traducir del árabe al español significa traducir entre dos idiomas lingüística e ideológicamente lejanos, dos lenguas entre las cuales existe un abismo amplio, y la tarea del traductor aquí es intentar todo lo que pueda tender puentes entre estos dos idiomas. Y puesto que cada uno tiene sus respectivas peculiaridades y características culturales y lingüísticas, el traductor que quiera intervenir en este campo de la traducción tiene que reunir dos requisitos fundamentales: ser bilingüe y bicultural.

El árabe y el español son dos lenguas pertenecientes a dos familias lingüísticas distintas, ya que el árabe es una lengua semítica mientras que el español es una lengua latina. Esta diferencia en los orígenes de las dos lenguas causa muchos problemas a la hora de verter un texto del español al árabe o viceversa, ya que cada lengua tiene sus respectivas estructuras

${ }^{1}$ A. Hurtado Albir, Traducción y traductología: introducción a la traductología, Madrid, Cátedra, 2001, p. 21. 
lingüísticas y eso influye mucho en el proceso de la traducción. Cuando el alumno está ante un texto árabe y quiere ponerlo en español intenta ser lo mas fiel posible; es decir, intenta conservar los dos componentes fundamentales del material textual, el contenido y el estilo, sin querer sacrificar ninguno de ellos, intentando con esto lograr la versión más fiel al original.

Creemos que en cualquier traducción entre estas dos lenguas es casi imposible conservar los dos componentes del material textual. Siempre se tiene que modificar el estilo del texto original por la sencilla razón de que la oración árabe y la española tienen dos estructuras morfosintácticas distintas y, como se sabe, la tarea del traductor es siempre intentar adecuar estos dos componentes a aquellos de la lengua receptora, por lo que se tiene que modificar el estilo para adecuarlo lo más posible, ya sea al árabe o al español.

Éste no es el caso de la traducción efectuada entre dos lenguas pertenecientes a la misma familia lingüística, como ocurre con el español y el portugués, por ejemplo. Si estamos ante un texto en español y queremos verterlo al portugués, seguramente nos van a surgir menos problemas de los que surgen entre el árabe y el español por una razón muy obvia, la cual es que la oración española y la portuguesa tienen el mismo orden básico de palabras y parecidas estructuras por ser las dos perteneciente a la misma familia lingüística. Seguramente también los problemas del mal entendimiento de la terminología cultural serían muchos menos porque los pueblos que hablan estas dos lenguas pertenecen casi a las mismas tendencias ideológicas, no siendo éste el caso del árabe y del español ${ }^{2}$. En cualquier caso, en este artículo vamos a dedicarnos esencialmente a estudiar el problema lingüístico en la traducción sin adentrarnos en el problema cultural e ideológico.

\section{ORACIÓN VERBAL FRENTE A ORACIÓN NOMINAL}

Lo que más caracteriza a la oración árabe es ser una oración verbal en la mayoría de sus combinaciones lingüísticas, mientras que la española es preferentemente una oración nominal. Esta diferencia en la estructura sintagmática se considera uno de los problemas fundamentales que afrontan los estudiantes árabo-parlantes a la hora de verter un texto del árabe al español.

En lo que sigue, intentaremos arrojar luz sobre las características de la oración árabe y sus clases, cotejándola con la española, para luego destacar dónde exactamente se suelen cometer los errores en la traducción por los estudiantes hablantes de árabe.

Tanto en árabe como en español, las oraciones pueden ser verbales (con anteposición del verbo al sintagma nominal sujeto) o nominales (con anteposición del sintagma nominal sujeto con respecto al verbo principal de la oración), aunque el orden de las palabras básico de ambas lenguas es diferente (VSO en árabe, SVO en español). Esta diferencia determina, como es lógico, una preferencia estilística por la oración verbal en árabe frente a la lengua española.

\footnotetext{
${ }^{2}$ En realidad, los problemas a que nos referimos también se dan en la traducción entre lenguas pertenecientes a la misma familia, si bien de modo menos acentuado. En la familia romance, basta con mencionar los diferentes usos verbales y oracionales en español y portugués (como por ejemplo, la tendencia del portugués a usar la afirmación o la negación del verbo en las respuestas a las preguntas de tipo sí/no, frente a la preferencia adverbial del español) o las restricciones en el orden de la palabras básico del francés a la mayor permisividad de la lengua española.
} 


\subsection{La oración verbal}

En la oración verbal árabe, el verbo siempre se coloca a la cabeza, y marca una acción (o un estado) que es suficiente en sí mismo, ya que la mención del sujeto o de los complementos no es más que una añadidura secundaria ${ }^{3}$.

Esta posición privilegiada del verbo le confiere un gran valor afectivo concreto, y puesto que el verbo está colocado en la cabeza de la oración, responde directamente a la pregunta siguiente: “QQué ha pasado?” Considérese el siguiente ejemplo:

$$
\begin{array}{ll}
\text { rakiba al-faris al-hisan } & \\
\text { montó } & \text { el caballero caballo }
\end{array}
$$

El caballero montó el caballo

En esta oración árabe lo más importante es la acción de montar el caballo. Así pues, como vemos, el verbo cobra la máxima importancia entre los otros componentes de la oración.

Asimismo, la oración verbal es muy empleada en árabe, mucho más que la nominal, sobre todo en las narraciones, puesto que da impresión de vida y movimiento a los textos narrativos.

La importancia del papel que desempeña el verbo árabe en la oración puede aparecer claramente en la comprobación siguiente: en español, el verbo puede ir siempre acompañado por un adverbio que efectúa una modificación en su significado o en el de todo el sintagma verbal; en cambio, un verbo árabe cuidadosamente elegido puede dar y reunir el significado del verbo y del adverbio a la vez, como por ejemplo:

$$
\begin{aligned}
& \text { atqana 'amalahu } \\
& \text { Perfeccionó su trabajo } \\
& \text { Ha hecho su trabajo bien }
\end{aligned}
$$

$\begin{array}{lr}\text { yanduru } & \text { aklahu } \\ \text { Es un hecho raro } & \text { comérselo } \\ \text { Se come raramente } & \\ \text { istashala } & \text { kasruhu } \\ \text { Lo ha encontrado fácil } & \text { romperlo }\end{array}$

En estos tres ejemplos, los tres verbos árabes reúnen el significado del verbo más el del adverbio, no estando este fenómeno lingüístico tan extendido en español. En tales frases los estudiantes árabo-parlantes no suelen realizar la traducción más próxima porque se esfuerzan en buscar un verbo que reúna el significado del verbo más el del adverbio a la vez, pero no lo logran porque es un fenómeno lingüístico no asimilable en español. Por eso se tiene que aclarar siempre a los alumnos dentro del aula que a la hora de verter un texto del árabe al español o viceversa tienen que librarse del todo de la influencia que ejerce la lengua materna en ellos y hacerles darse cuenta de que los dos idiomas entre los cuales se efectúa el proceso de la traducción son distintos mediante ejercicios de traducción que se les dan en la clase.

\footnotetext{
${ }^{3}$ R. Fortunato, Gramática árabe-española con crestomatía de lecturas árabes, Madrid, EDI-6, p. 64.
} 


\subsubsection{Observaciones estilísticas sobre la oración verbal árabe}

El árabe utiliza preferentemente la forma verbal de la oración mientras que el español emplea la forma nominal. El árabe es sintético y conciso en tanto que el español es analítico y preciso: el árabe expresa siempre con una sola palabra una idea compleja, así pues es conciso; en cambio el español expresa cada elemento de una idea compleja por una palabra particular, por lo tanto es preciso ${ }^{4}$. Por ejemplo:

$$
\text { 'Azamtu 'ala al-firar min al-dunya ila al-nisk }
$$

He tomado la decisión de escapar de la vida mundana a la vida de devoción

He tomado la decisión de renunciar a la vida mundana para llevar una vida de devoción.

Observando solamente la longitud de la oración árabe y la española, podemos darnos cuenta directamente de que el árabe es una lengua concisa que expresa una idea compleja mediante pocos elementos léxicos, ya que la idea que expresa el árabe en este ejemplo mediante cuatro palabras y dos partículas, el español la expresa mediante ocho palabras y partículas.

Otra diferencia estilística interesante es que la oración verbal árabe se inclina por repetir el verbo, frente al uso habitual en español. Podemos observar diferentes formas de repetición:

- Repetición del mismo verbo:

$$
\begin{aligned}
& \text { qala al-rayul fi-ma yaqul } \\
& \text { Dijo el hombre entre lo que dice } \\
& \text { El hombre ha dicho entre otras cosas }
\end{aligned}
$$

$$
\begin{aligned}
& \text { hasala ma hasal } \\
& \text { Pasó lo que pasó } \\
& \text { Y puesto que es así, no podemos hacer nada }
\end{aligned}
$$

- Repetición de verbos sinónimos u homófonos:

(8) fasihtu bihim, algut alguț, ilhquni, adrikuni Grité a ellos, socorro socorro, ayudadme, salvadme Les grité "Socorro, ayudadme, salvadme"

- Repetición bajo la forma de un participio de adjetivo:

$$
\begin{aligned}
& \text { tara tauruhu } \\
& \text { rebeló } \quad \text { su rebelión } \\
& \text { Se ha puesto fuera de sí }
\end{aligned}
$$

(10) 'ala albagi tadur al-dawa'r sobre el tirano circulan los círculos

El tirano soportará las consecuencias de sus hechos

- Repetición bajo la forma de un nombre de acción:

$$
\text { qatala qitala al-'abtal }
$$

\footnotetext{
${ }^{4}$ J. Nayyar, Traité de tradcutión, Beirut, Dar al-Mashriq, 1986, p. 16.
} 
luchó luchas de héroes

Guerreó como los héroes

En español la repetición se evita, mientras que en árabe es de uso habitual y tiene como objetivo insistir sobre la duración, la manera o la intensidad de la acción, pudiendo contribuir también a la rima y la armonía de la oración.

Otra cuestión estilística diferenciadora se establece porque en árabe a veces encontramos dos verbos coordinados que forman dos proposiciones. Estos dos verbos suelen ir unidos por una letra copulativa, pero en realidad el primero de ellos es auxiliar y el segundo lo completa; es decir: los dos expresan la misma idea. Frente a esta amplitud de dos proposiciones en árabe, el español prefiere la simplicidad de una sola:

tumma fa'azamtu
entonces padajaltu
Entonces, he decidido entrar

\subsection{La oración nominal}

Aunque la oración árabe es una oración verbal en la mayoría de sus casos, se puede hallar en árabe frases nominales (muy poco usadas) que se utilizan normalmente para dar más énfasis al nombre o al pronombre con el cual empieza la oración, y es muy conveniente sacar este matiz a la luz a la hora de verter una oración nominal del árabe al español, puesto que hay en árabe una diferencia considerable entre la frase verbal: rakiba al-faris ("montó el caballero") y la oración nominal al-faris rakiba ("el caballero montó"), ya que en la primera oración se enfatiza sobre la acción verbal montar mientras que en la segunda se enfatiza sobre el nombre sujeto el caballero.

Esta distinción existe en la lengua española justamente en sentido contrario, siendo la oración nominal la más habitual y la verbal la más enfática.

Como ya hemos visto, cada una de las frases árabes y españolas tienen sus respectivas peculiaridades y características por la pertenencia a dos lenguas con un origen distinto. Pese a la larga estancia de los árabes en España, que duró casi ocho siglos, la influencia lingüística del árabe en el español se limita a préstamos lingüísticos de algunos elementos léxicos cuyo número no supera las cuatro mil palabras, pero en el nivel de la estructura sintagmática, el árabe no ejerció influencia ninguna a este respecto.

Uno de los problemas fundamentales que suelen tener los estudiantes universitarios árabo-parlantes en la traducción es no respetar las peculiaridades de estas dos lenguas, ya que en la mayoría de los casos suelen acudir a la traducción literal y convierten la oración nominal española en verbal y la verbal árabe en nominal, hasta el punto de que algunas traducciones nos hacen saber directamente que están hechas por un traductor hablante de árabe, como figura muy obviamente en el ejemplo siguiente, que es una traducción de un alumno nuestro árabo-parlante, hecha al español a partir de un texto árabe:

$$
\begin{aligned}
& \text { sarraha wazir al jariyiyya al urduni bianna ra is alwuzara`sayaqum biziyara rasmiyya ila } \\
& \text { Suriya al-sahr al muqbil. } \\
& \text { Ha declarado el ministro de asuntos exteriores jordano que el primer ministro va a } \\
& \text { emprender una visita a Siria el mes próximo. (El ministro de asuntos exteriores jordanos } \\
& \text { declaró que el primer ministro visitará Siria el mes que viene.) }
\end{aligned}
$$


(14) naffadat quwat al-' ihtilal huyuman yawwiyyan 'ala yanub Bagdad dedda ansar alra' is al 'iraqi al sabiq.

Ha llevado a cabo la fuerza de la ocupación un ataque aéreo al sur de Bagdad, en contra de partidarios del ex presidente iraquí. (La fuerza de ocupación ha llevado a cabo un ataque aéreo en el sur de Bagdad contra partidarios del ex presidente iraquí.)

A partir de estas dos versiones hechas al español por alumnos árabo-parlantes a partir de un texto árabe, se nota muy obviamente la influencia de la lengua materna, ya que lo que hizo el alumno en su traducción de estos fragmentos periodísticos fue seguir el orden de la oración árabe palabra por palabra, tal como está en el texto original árabe, sin tener en cuenta la peculiaridad de cada lengua. En otras palabras, el alumno hizo una arabización -si podemos decirlo así- de la estructura de la oración española, adecuándola a la estructura de la árabe y convirtiéndola en una oración encabezada por el verbo.

Los mismos errores se cometen por los mismos alumnos a la hora de verter un texto del español al árabe, ya que lo que hacen en esta clase de traducción es adecuar la estructura de la oración árabe a la de la española, convirtiendo la oración árabe en una nominal.

Se dice que la mejor traducción es aquella que hace sentir al lector que el texto vertido fue escrito originariamente en la lengua receptora; en otras palabras, hacer sentir al lector que no esté leyendo un texto traducido. La pregunta que se plantea aquí es cómo podríamos hacer que el alumno adquiera esta competencia traductora.

Creo que la mejor estrategia que se podría adoptar en nuestro caso es enseñar al alumno cómo librarse de la influencia de la lengua materna y eso se logra por medio de un entrenamiento intensivo de traducción sobre textos árabes y españoles. La intervención del profesor en este tipo de traducción es imprescindible para aclarar la diferencia entre los dos idiomas objeto de la traducción y también para enseñarles a los alumnos las estrategias por medio de las cuales se podría adecuar el texto y "domesticarlo" lingüísticamentes, adecuándolo a las estructuras de la lengua receptora.

\section{EL SISTEMA VERBAL DEL ÁRABE EN COMPARACIÓN CON EL DEL ESPAÑOL}

Otro problema que no tiene menos importancia que los que hemos mencionado antes es aquel de encontrar el tiempo verbal equivalente entre el árabe y el español o viceversa a la hora de traducir, ya que muchos alumnos no aciertan en la elección del tiempo verbal adecuado y equivalente entre los dos idiomas. Esto exige que el alumno de traducción entienda a fondo el uso de los tiempos verbales en los idiomas entre los cuales se efectúa el proceso de la traducción para poder alcanzar el máximo grado de fidelidad.

Los tiempos verbales en árabe y español representan un problema serio ante el alumno por una simple razón: las dos lenguas no tienen el mismo sistema y división de los tiempos verbales. En la conjugación árabe existen únicamente tres tiempos fundamentales: perfecto, imperfecto e imperativo. En el imperfecto están contenidos el presente y el futuro. Los demás modos y tiempos correspondientes a la conjugación española se obtienen

\footnotetext{
${ }^{5}$ Esta expresión se debe a L. Venuti, The translator's invisibilty, Londres, Routledge, 1995, p. 87.
} 
anteponiendo al pretérito y al presente o bien ciertas partículas o bien el verbo auxiliar "kana" (ser).

\subsection{El imperfecto indicativo}

\subsubsection{Sentido del presente}

El imperfecto tiene el valor ordinario del presente puesto que expresa un estado o una acción en curso de realización, o bien un hecho que dura o una verdad de orden general ${ }^{6}$.

$$
\text { qala lahu waladuhu: mali araka hazinan }
$$

Su hijo le dijo: ¿por qué te veo triste?

El imperfecto se encuentra con el sentido del presente después de las partículas de negación: laysa, ma, la, y después de la partícula $l$ - de énfasis, como por ejemplo:

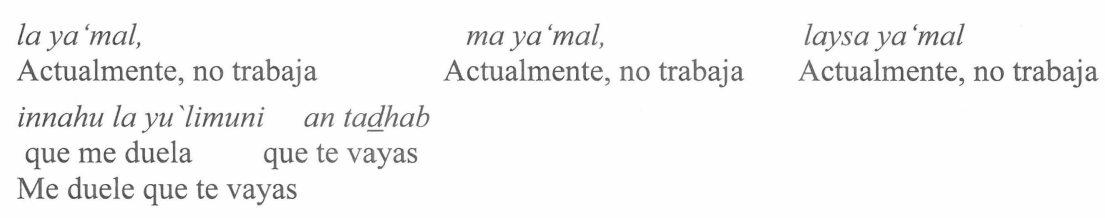

Actualmente, no trabaja Actualmente, no trabaja

Actualmente, no trabaja

laysa ya'mal

\section{innahu la yu 'imuni an tadhab}

que me duela que te vayas

Me duele que te vayas

El imperfecto tiene el sentido del futuro después de los adverbios de interrogación ha-a, la partícula de negación lan, los adverbios de tiempo $s$-sawf y el adverbio de duda qad:

a'atruduhu ba'da an qalaha

Le echaré después de que lo haya dicho

El imperfecto también da el sentido del futuro en diversos casos donde el contexto indica claramente la posterioridad del hecho expresado por el verbo. Esta localización de lo incumplido en el futuro expresa matices muy sutiles en la traducción española:

- Matiz de un futuro próximo:

sa-adjulu al-ana

Voy a entrar, ahora mismo

- Matiz de cierta capacidad de realizar la acción (expresado por diferentes maneras):

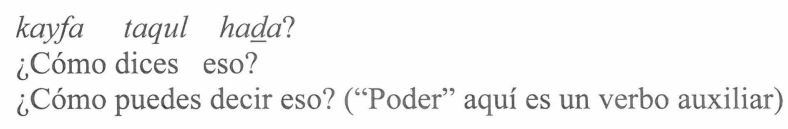

- Matiz de condicional:

$$
\begin{aligned}
& \text { yawaddu ahadahum law yu'ammira alfa sana } \\
& \text { quería cada uno de ellos si viviría mil años } \\
& \text { Cada uno de ellos quisiera vivir mil años }
\end{aligned}
$$

\subsubsection{Sentido del pasado}

El imperfecto tiene el sentido del pretérito perfecto o indefinido después de la partícula de negación lam:

\footnotetext{
${ }^{6}$ F. Ribosa, Gramática árabe-española, Madrid, Edelsa, 1986, p. 100.
} 
(22) lam ara aktar minka yamala

No he visto a nadie más bello que tú

El imperfecto marca una acción habitual y tiene el sentido del imperfecto español después del verbo kan: kana la yufariqu baytahu No salía de su casa

Con un adverbio de tiempo que marca el pasado, lo incumplido corresponde al imperfecto:

lima taqtuluna anbia'a Allah min qabl

¿Por qué matábais los mensajeros de Dios en otro tiempo?

\subsection{El tiempo pretérito}

Normalmente el pretérito en árabe tiene el sentido del pasado. Cinco tiempos diferentes le corresponden en español: pretérito perfecto, pretérito indefinido, pretérito imperfecto, pretérito pluscuamperfecto y pretérito anterior.

La frase árabe akaltu al jubz podría tener seis traducciones: comi / he comido / habia comido / hube comido / comía el pan. Para crear una frase verbal que corresponda cien por cien al tiempo en español, se utiliza el pretérito o el imperfecto del verbo que se trata de conjugar con el auxiliar kana (ser) o con ciertas partículas como explicamos a continuación.

\subsubsection{Tiempo presente}

Lo incumplido solo equivale en árabe al presente de indicativo:

$$
\begin{aligned}
& \text { yaktub } \\
& \text { Él escribe }
\end{aligned}
$$

También se expresa el presente en árabe por el participio activo precedido de nombre o pronombre personal y se traduce al español por el presente de indicativo:

$$
\begin{aligned}
& \text { Ahmad na'im huna } \\
& \text { Ahmad está dormido aquí }
\end{aligned}
$$

\subsubsection{Pretérito imperfecto}

Se forma anteponiendo el pretérito del verbo kana al presente o al participio activo del verbo que se quiere conjugar:

$$
\begin{aligned}
& \text { kana yal 'ab } \\
& \text { Jugaba } \\
& \text { kana ya'qul } \\
& \text { Comía }
\end{aligned}
$$

\subsubsection{Pretérito indefinido y pretérito perfecto}

Ambos tienen su correspondiente en el pretérito.

akalna

Ellas comieron / Ellas han comido

$\mathrm{O}$ en el imperfecto precedido de la partícula negativa lam (no). 

lam yal'aba Ellos dos no jugaron / no han jugado

\subsubsection{Futuro imperfecto}

Se forma anteponiendo al imperfecto la partícula sa que indica un futuro próximo, saufa que indica un futuro lejano o la partícula lan que indica un futuro negativo.

(31) saaftah $a l-b a b$

Voy a abrir la puerta (futuro próximo)

(32) saufa adhab

Iré

lan adjul

No entraré

\subsubsection{Pretérito pluscuamperfecto}

Se forma anteponiendo el pretérito del verbo kana (ser) al pretérito del verbo que se quiere conjugar, intercalando entre ambos la partícula qad (ya).

(34) kana qad dajala

Ya había entrado

\subsubsection{Futuro perfecto}

Se forma anteponiendo el imperfecto del verbo kana (ser) al pretérito del verbo que se quiere conjugar, el cual irá precedido de la partícula qad.

$$
\text { yakun qad jaraya }
$$

Habrá comido

\subsection{Modo potencial}

Se forma con el pretérito del verbo kana precedido de la partícula la, seguido del imperfecto del verbo que se trata de conjugar.

(36) law ana makanuka, lakuntu darastu Yo que tú, estudiaría más

\subsection{Modo imperativo}

Se expresa con el imperativo del verbo que se trata de conjugar y tiene sus reglas especiales de conjugación.

$$
\begin{aligned}
& \text { ujruy } \\
& \text { Sal }
\end{aligned}
$$

\subsection{Modo subjuntivo}

\subsubsection{Presente}

Se forma con el imperfecto precedido de la partícula an (que).

$$
\begin{aligned}
& \text { urid an tajruy } \\
& \text { Quiero que salgas }
\end{aligned}
$$




\subsubsection{Pretérito imperfecto}

Se forma con el imperfecto de indicativo y el presente de subjuntivo.

\section{kana yurid an tajruy}

Quería que salieras

Pero si la oración es condicional, se formará con el imperfecto de indicativo precedido de una de las dos partículas la o law.

law ta 'rif ahmiyyat al imtihan ladarasta aktar

Si supieras la importancia del examen, estudiarías más

\subsubsection{Futuro imperfecto}

Se puede expresar con el pretérito o con el imperfecto precedido de un pronombre o partícula condicional.

$$
\begin{aligned}
& \text { man yadrus yanyah } \\
& \text { El que estudia aprobará } \\
& \text { in tadrus tanyah } \\
& \text { El que estudia aprobará }
\end{aligned}
$$

\subsubsection{Pretérito perfecto}

Se expresa con el pretérito del verbo que se quiere conjugar precedido de la partícula an (que).

la ara annahu darasa

No veo que haya estudiado

Si es condicional, se formará con el pretérito del verbo que se quiere conjugar, solo o precedido del imperfecto del verbo kana (ser).

$$
\begin{aligned}
& \text { sa 'ukafi 'u man darasa } \\
& \text { Premiaré al que haya estudiado }
\end{aligned}
$$

\subsubsection{Pretérito pluscuamperfecto}

Se expresa con el pretérito del verbo que se desea conjugar precedido del pretérito del verbo kana anteponiendo a éste la partícula la o lau cuando es condicional.

law kana darasa lanayaha

Si hubiera estudiado, habría aprobado

\section{CONCLUSIÓN}

Como ya hemos comentado antes, el problema frecuente de los estudiantes áraboparlantes a la hora de verter un texto del árabe al español o viceversa es no acertar en la elección del tiempo verbal equivalente en la lengua receptora y eso puede ser debido a distintos motivos. Uno de estos motivos es que el alumno se deja influir por su lengua materna o puede que no haya entendido correctamente el tiempo, o que no haya entendido bien los usos exactos de los tiempos verbales en español.

Por ello creo que la tarea fundamental del profesor en las primeras clases de traducción (cuando se trata de una asignatura de traducción árabe español o viceversa) es explicar a fondo los tiempos verbales en ambas lenguas, comparando entre ellas y aclarándolo todo 
con ejemplos, destacando poco a poco las diferencias entre las dos lenguas a todos los niveles lingüísticos mientras las va explicando, hasta que el alumno empiece a adquirir sus estrategias propias para saber recorrer el proceso traductor y obtener, así, la competencia traductora.

\section{REFERENCIAS BIBLIOGRÁFICAS}

FORTUNATO, R., Gramática árabe-española con crestomatía de lecturas árabes, Madrid, EDI-6.

HURTADO, A., Albir, Traducción y traductología: introducción a la traductología, Madrid, Cátedra, 2001.

NAYYAR, J., Traité de tradcutión, Beirut, Dar al-Mashriq, 1986.

RIBOSA, F., Gramática árabe-española, Madrid, Edelsa, 1986.

VENUTI, L., The translator's invisibilty, Londres, Routledge, 1995. 
